جامعـة نيويورك أبـوظـبي $\stackrel{\uplus}{i}$ NYU $\mid$ ABU DHABI

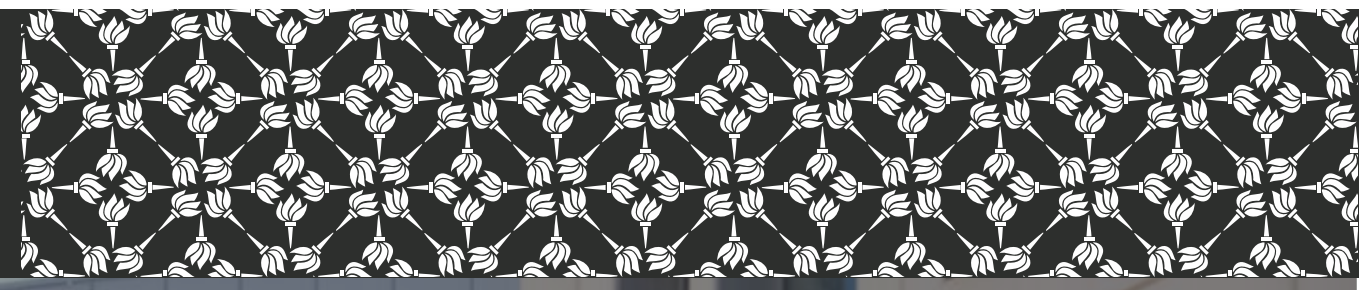

\title{
The Determinants of Multilateral Bargaining: A Comprehensive Analysis of Baron and Ferejohn Majoritarian Bargaining Experiments
}

\author{
Andrzej Baranski and Rebecca Morton
}

\author{
Working Paper \# 0037 \\ January 2020
}




\title{
The Determinants of Multilateral Bargaining: A
}

\section{Comprehensive Analysis of Baron and Ferejohn}

\section{Majoritarian Bargaining Experiments}

\author{
Andrzej Baranski ${ }^{* 1}$ and Rebecca Morton*1,2 \\ ${ }^{1}$ Division of Social Science, NYU Abu Dhabi \\ ${ }^{2}$ Department of Politics NYU
}

January 14, 2020

\begin{abstract}
We collected and analyzed the data sets of all majoritarian Baron and Ferejohn (1989 Am. Pol. Sci. Rev.) experiments through 2018. By exploiting the variation of experimental parameters such as group size and discount factor we are able to test whether or not the theoretical point predictions and comparative statics hold and find virtually no support for the theory. Novel findings are reported about the effect of group size and discounting on distribution of the surplus, the proposer's share, agreement delay, and voting behavior. We also report on off-equilibrium behavior (after subjects fail to agree) and identify strong history-dependent behavior in the form of punishment and loyalty to previous proposers.
\end{abstract}

\footnotetext{
*We would like to thank Marina Agranov, Anthony Bradfield, Daniel Diermeier, Guillaume Frechette, Sean Gailmard, Tanushree Jhunjhunwala, John H. Kagel, Luis Miller, Maria Montero, Hankyoung Sung, and Chloe Tergiman for kindly sharing their data sets and explaining their structure in detail to us. Without their help, it would not have been possible to write this article. Sima Basel and Luis Quesada offered excellent research assistance. All errors remain our own.
} 


\section{Introduction}

In 1989, David P. Baron and John A. Ferejohn published an influential article entitled "Bargaining in Legislatures". Their goal was to provide a game-theoretic foundation for the analysis of legislative bargaining in order to characterize the distribution of payoffs within legislatures. In its original form, the authors framed their model as an abstraction for problems of "distributive or expenditure policy in a unicameral, majority rule legislature not favoring any member of the legislature or any particular outcome". Since then, a plethora of applications and theoretical extensions have been set forth in and beyond political science (Eraslan and Evdokimov, 2019) and their model has been the subject of a vast number of experimental investigations which are the focus of this paper.

We collected and aggregated the data sets for all published experimental studies through 2018. By enlarging the sample size and homogenizing the analysis, we are able to answer several open questions in the literature and determine with enhanced statistical power the significance of existing results. In particular, we study the effect of group size and discounting on the model's point predictions and comparative statics. We also provide a comprehensive analysis of the scope and nature of retaliation when committees delay agreements, an aspect that has been typically overlooked. In our analysis we control for learning with experience, institutional variables such as the possibility to communicate, and the effect of monetary incentives (stake size) on bargaining outcomes relative to the fixed participation payment.

Baron and Ferejohn proposed a very simple and intuitive bargaining protocol. ${ }^{1}$ A group of three or more players bargain on how to divide one unit of wealth. Every member has the same probability of being recognized as the proposer. Once a proposal is submitted, it cannot be modified, and the group proceeds to a sequential vote where a simple majority of members in favor are required for approval. In case of rejection, a new bargaining round takes place with every member having the same chance of being recognized. Payoffs for each

\footnotetext{
${ }^{1}$ In this article we focus on the closed-amendment rule which has received wide attention. A version of the model where another player must agree to move a proposal for a vote is not discussed here.
} 
subsequent round are discounted equally by all subjects.

In this game, any allocation is a Nash equilibrium and survives subgame perfection (for patient enough players). By further restricting strategies to be history-independent, the authors characterize the stationary subgame perfect equilibrium (SSPE) which yields a unique distribution of payoffs. It predicts that only a simple majority of members will receive a positive share, i.e that minimal winning coalitions (MWC) will form. Proposers will offer coalition partners a share which makes them indifferent between accepting and the continuation value of the game. The equilibrium continuation value of the game decreases with discounting (e.g. the more impatient players are) and with the size of the committee. Given the exclusion of redundant members and players' impatience, proposers are able to extract a larger share of the pie (known as proposer power). Finally, agreements are reached without delay in equilibrium.

Most evaluations of the experimental evidence in the literature reach the conclusion that the evidence provides qualitative support for the model's key SSPE outcome predictions (see Palfrey (2016)). In general reviewing these results seem to suggest that proposer power exists but is moderate and substantially below theoretical predictions, MWCs are common but not universal, and most agreements are reached without delay. In our analysis, by pooling multiple data sets for the first time to investigate these effects, shows that there is actually only minor support of the theory's point predictions, comparative statics, and strategies implemented.

By exploiting the variation in experimental parameters (group size and discounting) across studies, we are the first to conduct a structural estimation of the model's predicted proposer share. Estimation results show little evidence of a good fit between theory and subject behavior.

Regarding the overall distribution of the surplus and the timing of agreements, we find that group size and impatience have an impact on the prevalence of MWCs and delay, where theory predicts no effect. For example, in experiments with seven players all-way 
splits and minimal winning coalitions are almost equal in proportion. Only in groups of five can we argue that MWCs are preponderant (almost 80 percent). These results violate the comparative static prediction of no group-size effect on the the prevalence of MWCs. Also, the probability of agreement delay increases as the penalty for disagreement decreases, which is quite intuitive, but not prescribed by theory.

One key feature regarding the bargaining process per se has been largely ignored in most of the existing literature: subject behavior when a disagreement has previously taken place. History independence of bargaining strategies (assumed for SSPE) requires players to not be spiteful against a previous proposer who excluded them from the distribution of the fund. We believe that the lack of history analysis (off-equilibrium behavior) is mainly due to the relatively small size of the subsample in question given that delay is quite uncommon. ${ }^{2}$ We find strong evidence for retaliation against previous proposers by subjects who did not agree with their offered share. Interestingly, we also find evidence of loyalty by those who were offered an acceptable share.

There is also wide variation in experimental design features such as the number of games played, subject payment scheme (i.e. random period payment or pay for all periods), strategy method versus direct response, and fund size, among others. Naturally, studies also use different metrics to report findings. Some focus on all proposals while others only on approved ones, and some further condition on proposals approved without delay. Certain studies report results for periods of play once subjects have gained experience while others pool all periods. Moreover, some studies define a player as being excluded by the proposer when she receives a share of 0 while others use a more lenient measure such as receiving less than 5 percent of the fund. All these differences may obscure comparing across studies. In this article we uniformly analyze the data from all published studies through 2018. We focus on treatments that are comparable with each other and close in spirit to the symmetric nature of the original model. ${ }^{3}$

\footnotetext{
${ }^{2}$ An exception is Fréchette et al. (2005b) whom report no evidence of retaliation for previous proposers.

${ }^{3}$ We include in our analysis treatments that yield symmetric predictions and in which the fund to distribute
} 


\section{Literature Review}

In this review section, we present a summary table with all known published studies in chronological order. In it, we include a brief description of the question being asked in the study, the parameters used (groups size, discount factor), and experimental design details. Our goal is to provide researchers with a birds-eye view of the literature and it's progression over the last three decades. We do not discuss in detail the results of each study because these are the focus of the analysis section. For historical purposes, and because it differs substantially from most BF experiments, we discuss in detail the first conducted experiment (McKelvey, 1991) in Subsection 2.1. We also devote Subsection 2.2 to review experiments with asymmetric players (and asymmetric predictions) because these are excluded from our main analysis.

is exogenous. We also incorporate treatments that allow for costless communication. 


\begin{tabular}{|c|c|c|c|c|}
\hline 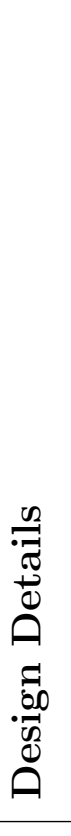 & 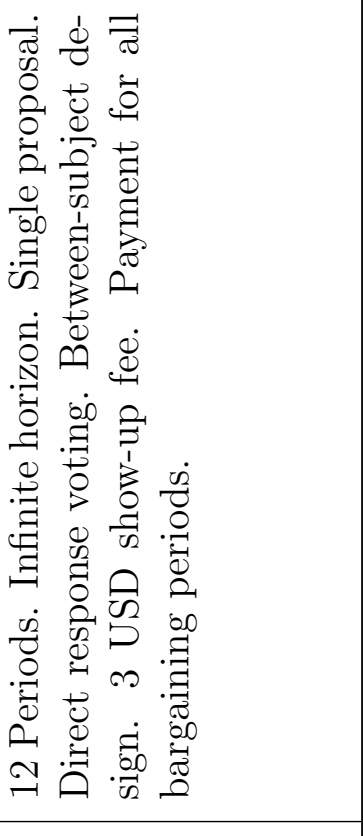 & 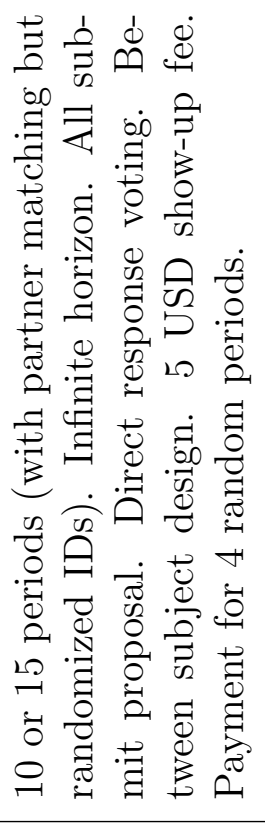 & 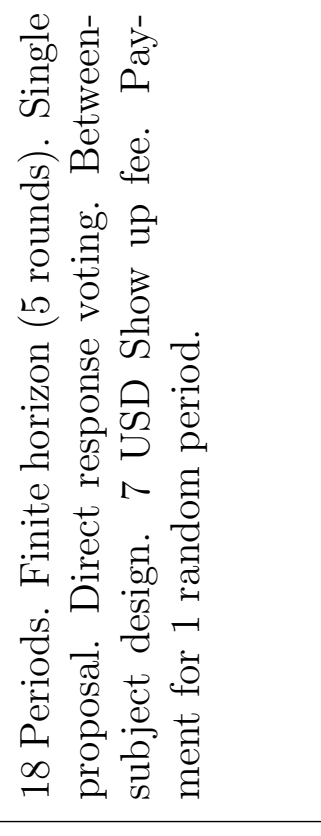 & 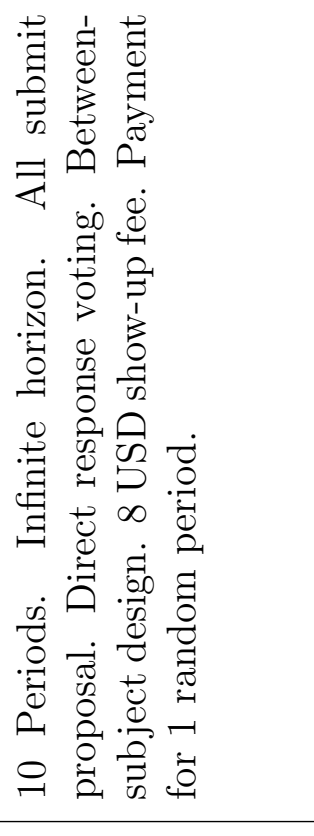 \\
\hline 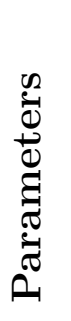 & 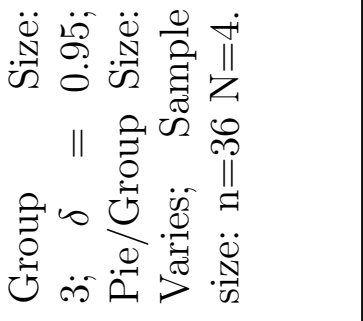 & 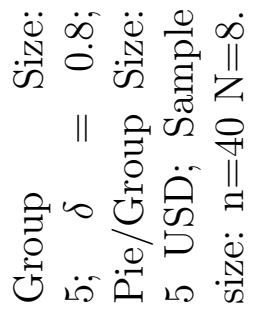 & 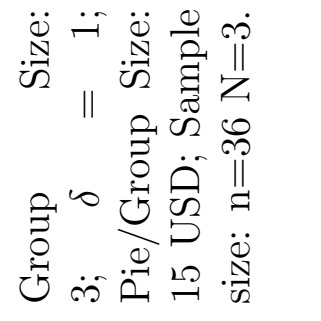 & 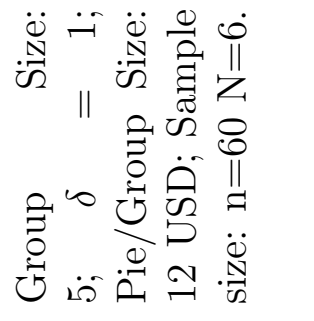 \\
\hline 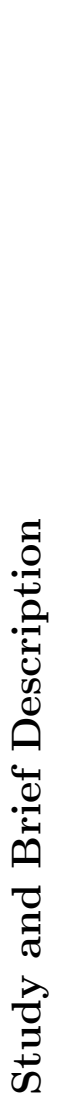 & 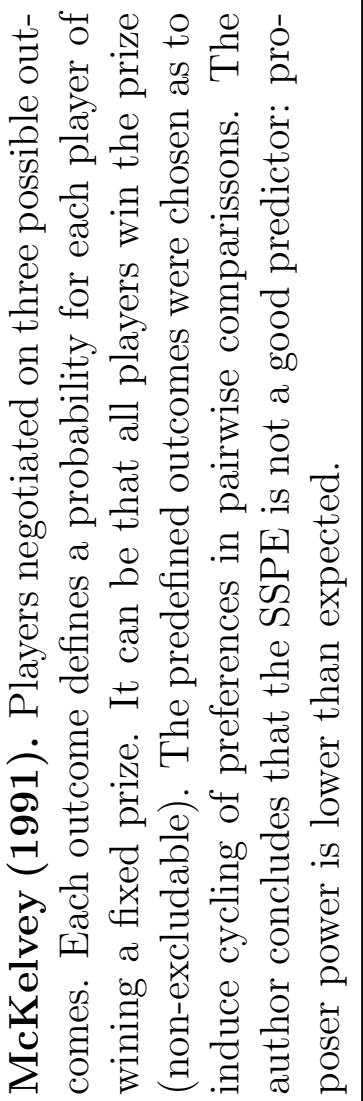 & 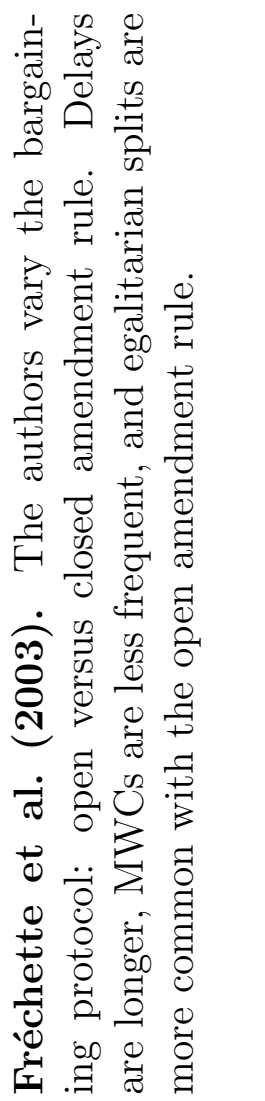 & 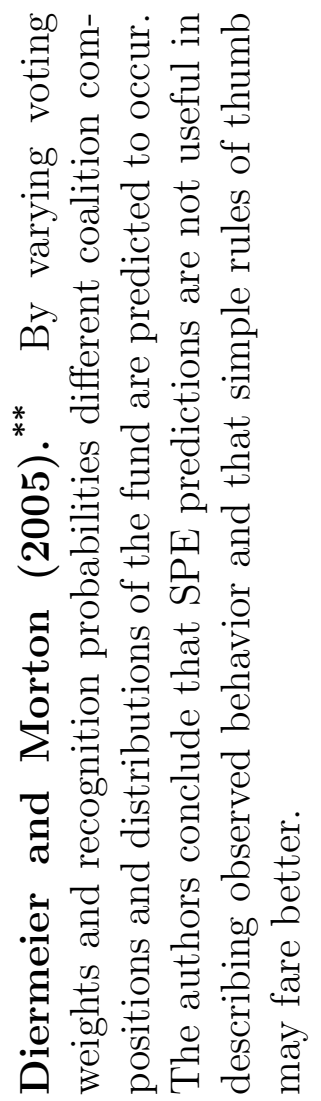 & 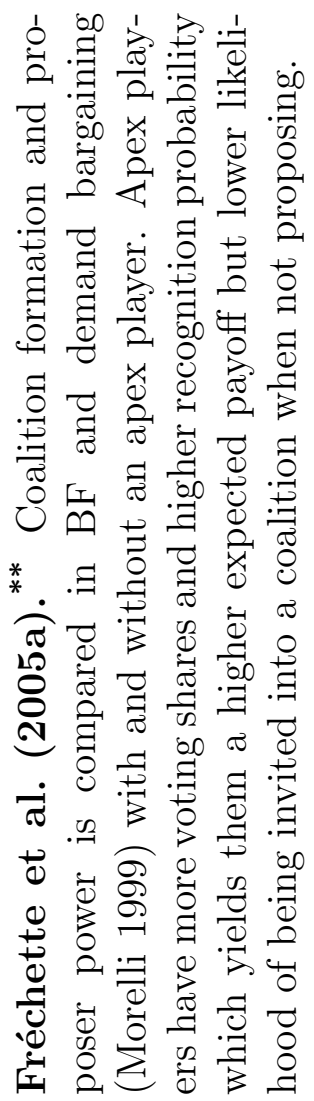 \\
\hline
\end{tabular}




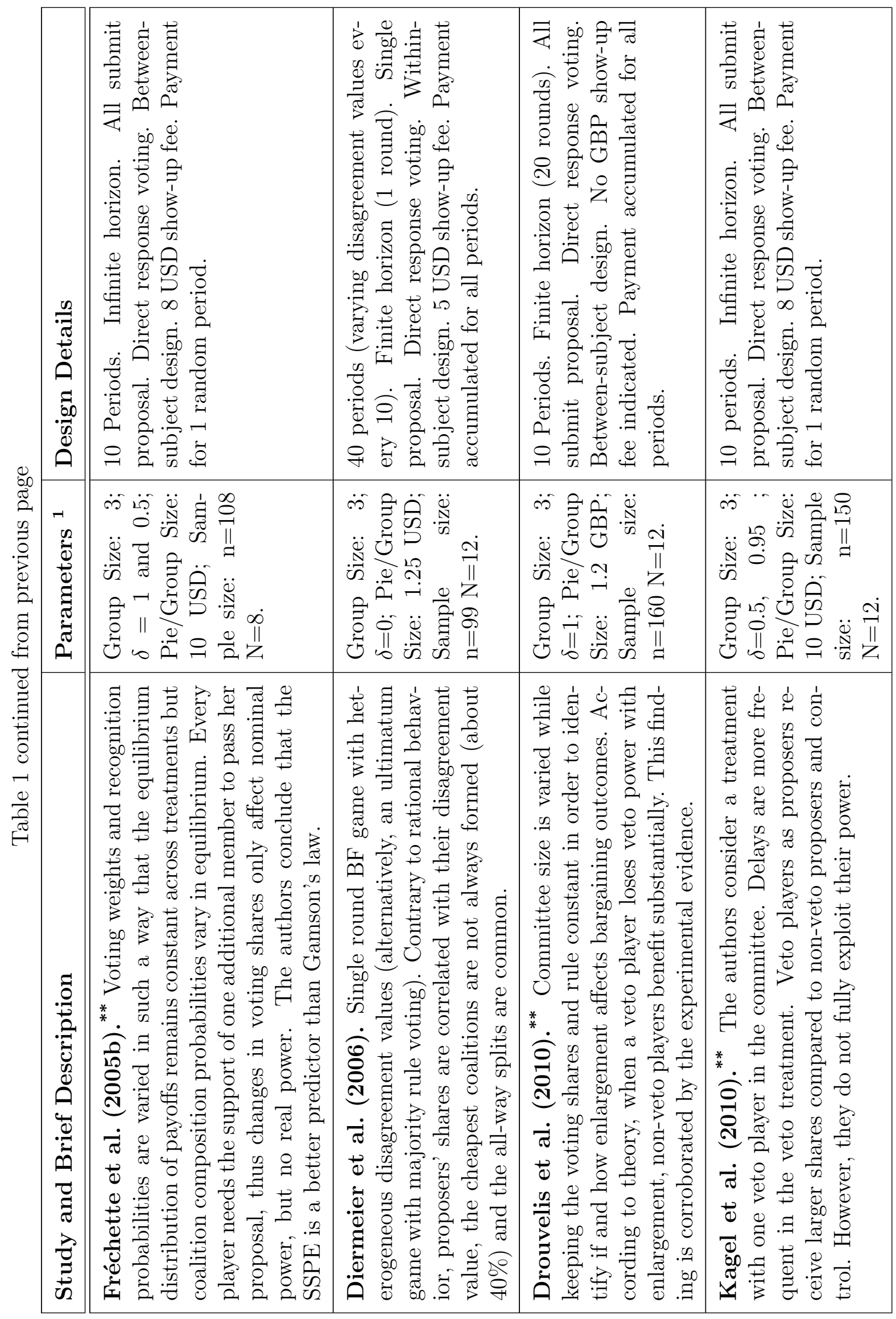




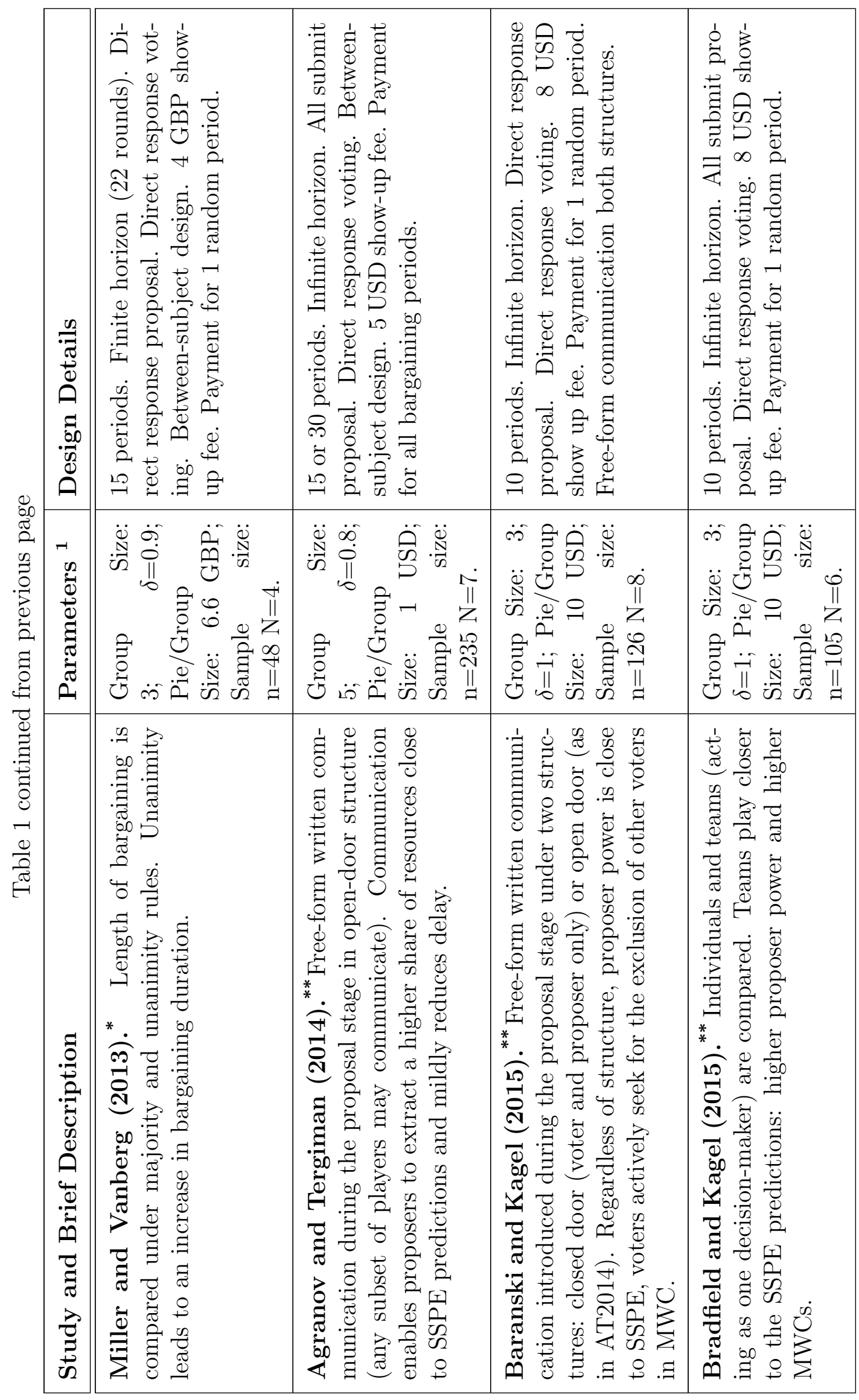




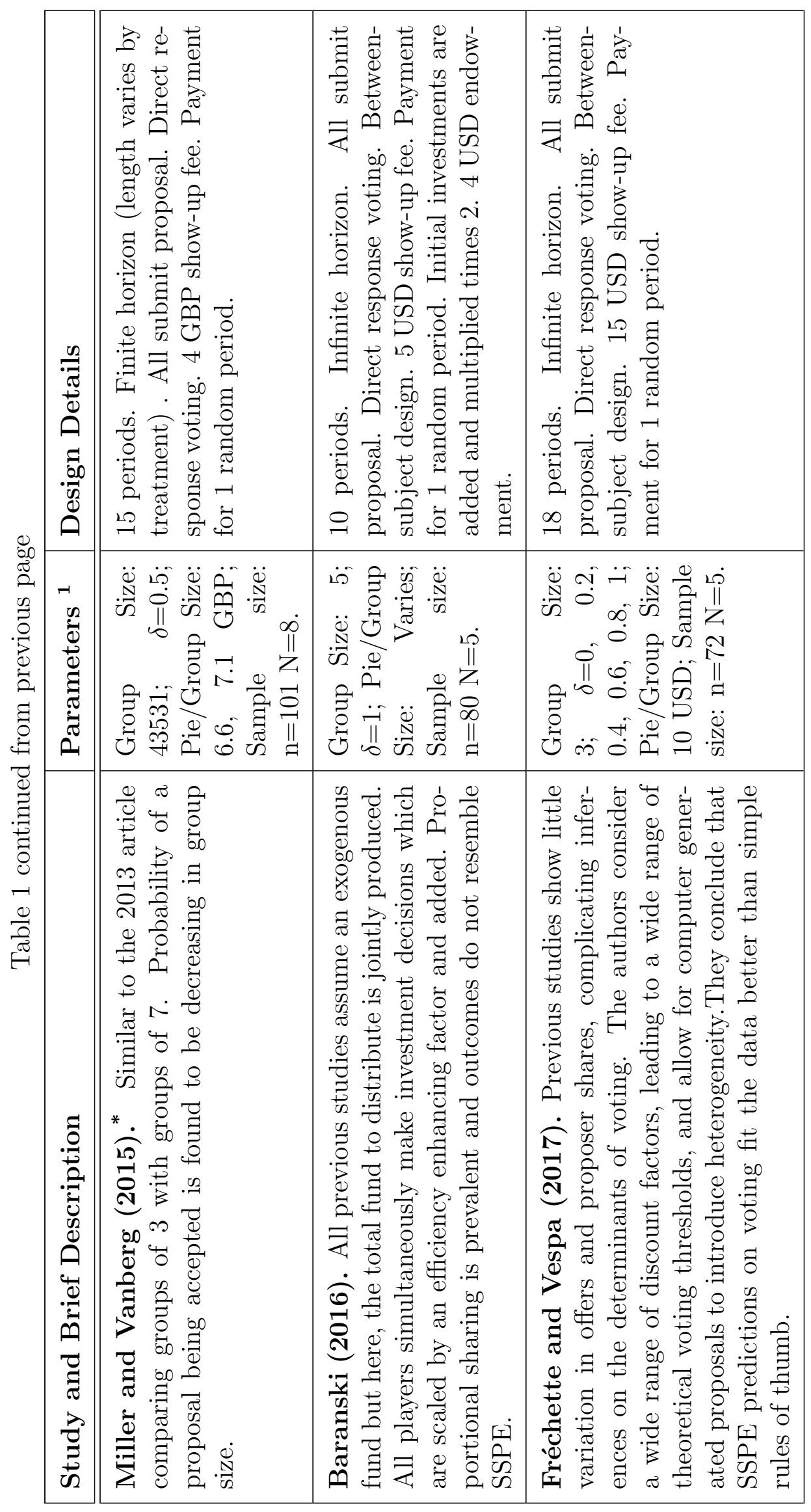




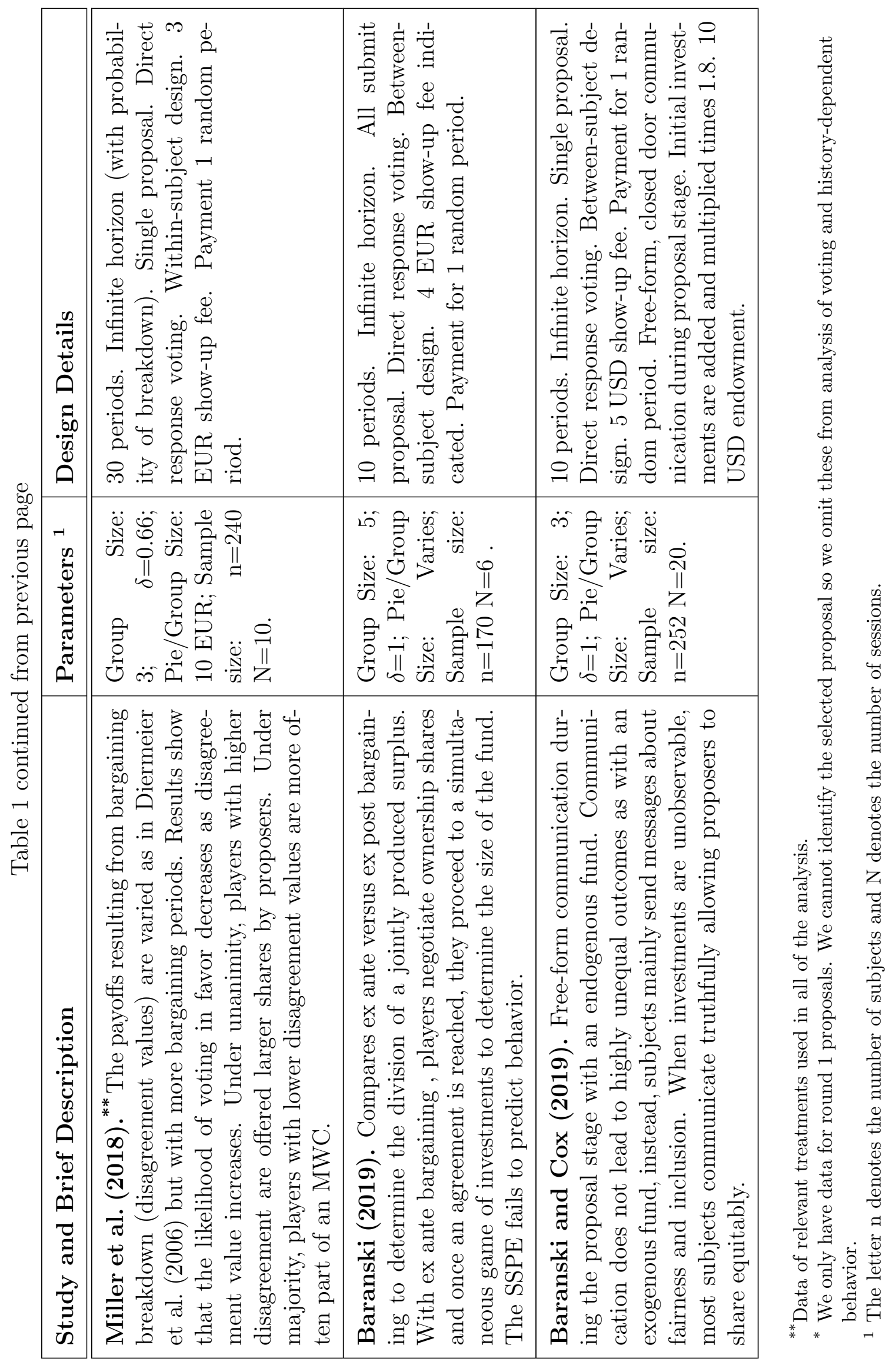




\subsection{The first experiment}

McKelvey (1991) is the first reported experimental test of a BF bargaining protocol (equiprobable recognition with majority rule) with an important distinction: proposals did not directly constitute a split of the pie, instead, they consisted of a vector or probabilities of winning a fixed prize of $\$ 2$ for each player. For example, the proposal $(0.9,0.5,0.1)$ is one in which player 1 has a $90 \%$ chance of winning $\$ 2$, player 2 has a $50 \%$ chance and player 3 has a $10 \%$ chance. Each draw was independent, all players could be winners. McKelvey allowed for only three possible proposals which were chosen as to induce cycling of preferences in pairwise comparisons. This game is quite far from the standard BF model where players divide a fixed sum of money. Nonetheless, the results obtained already foreshadowed what would be a constant in almost all experiments to follow: proposers did not take full advantage of their power as predicted by the SSPE. McKelvey concluded that "[t]he stationary solution ... does not do a terribly good job of explaining observed experimental data", and hinted at

the possibility of a non-stationary equilibrium "because of the fear of retaliation in successive rounds". In our subsequent analysis, we will focus on retaliation by studying bargaining in rounds following a rejection (see Section 4.5) in order to assess more carefully whether such a conjecture may help explain behavior.

\subsection{Asymmetric players: Shifting the balance of bargaining power}

The first experiments in which subjects bargain to divide a fixed amount of wealth were Diermeier and Morton (2005) and Fréchette et al. (2005b) in finite and infinite bargaining horizons, respectively. Both studies sought to understand how changes in voting shares and proposer recognition probabilities affect bargaining outcomes and considered three-person committees. In the finite horizon case, players with higher recognition probabilities have higher expected payoffs, thus are always excluded from the winning coalition when not proposing. For the infinite case, all players have the same continuation values regardless of 
differences in recognition (this only holds in three-person games). These studies also varied voting shares making sure that no player could unilaterally implement a division of the fund and that all players could, at some point, be part of a winning coalition. In other words, care was taken to vary nominal bargaining power, but not real power. ${ }^{4}$

The articles report some shared findings: proposers keep larger shares on average, but quite below the equilibrium predictions and MWCs are modal while all-way splits quite rare. ${ }^{5}$ Nevertheless, the studies differ in their findings regarding equilibrium mixing behavior of coalition partner choice. In a treatment with unequal recognition probabilities and unequal voting weights, Fréchette et al. (2005b) report that the proportion of observed coalitions matches the SSPE prediction quite close. On the other hand, Diermeier and Morton (2005) report for comparable treatments that "[t]he best account of the subjects' behavior is provided by a simple sharing rule where the proposer chooses any winning coalition and then distributes the pay-off equally among the coalition members. (pg. 224)".

Fréchette et al. (2005a) introduce a treatment in which one player (called apex player) holds a substantial voting weight such that real bargaining power shifts in her favor. ${ }^{6}$ Equilibrium specifies that base players form a coalition with the Apex player less often than with other base players, but the opposite holds true in the data. Base players seek a to form coalitions with the apex player around 70 percent of the time, when theory predicts only 25 percent. This anomaly appears to happen because base players are able to keep 46.9 percent of the fund when they form an MWC with the apex player, but only 31.9 percent with other base players.

We now turn to studies where one player has veto power, meaning every coalition must include them to pass. Note, however, that veto players cannot unilaterally impose a division of the total fund. Theory predicts that veto players earn more than base players both

\footnotetext{
${ }^{4}$ In the finite game, by varying the recognition probabilities, players had different continuation values.

${ }^{5}$ Diermeier and Morton (2005) report that in 42 percent of allocations in which all members receive a positive share are actually pittance coalitions since two members receive $\$ 22$ each and give $\$ 1$ to the their member. This seems to be an effect of the impossibility to divide the pie equally between coalition partners.

${ }^{6}$ This paper compares the model of demand bargaining with BF.
} 
as proposers and voters. ${ }^{7}$ Two concurrent studies Drouvelis et al. (2010) (finite bargaining horizon no discounting) and Kagel et al. (2010) (infinite bargaining horizon with discounting) set out to identify how a veto player affects bargaining outcomes, not only for veto players, but also for base players. Both studies reach qualitatively similar conclusions: veto players receive larger shares than non-veto players but these are substantially below the theoretical predictions. Drouvelis et al. (2010) further report on a treatment where a fourth player with inferior voting shares to all existing players is introduced to the group such that the former veto player is not essential in every coalition (i.e. the weak players may pass a proposal by joining forces). In accordance with the theory, the authors find that former veto players earn lower payoffs on average, and former weak players earn higher shares.

Table 2: Predicted and Observed Percentage of the Total Fund ${ }^{\mathrm{a}}$, Delay, and Minimum Winning Coalitions in Treatments with Veto Players

\begin{tabular}{lcccc}
\hline & \multicolumn{3}{c}{ Drouvelis et al. (2010) } & \multicolumn{2}{c}{ Kagel et al. (2010) } \\
\cline { 2 - 5 } & Predicted & Observed & Predicted & Observed \\
\hline Shares (\% of fund) & 98 & 67 & 92.4 & 62 \\
Veto Player is Proposer & 98 & 61 & 79.8 & 52 \\
Veto Player not Proposer & 100 & 72 & 100 & 59 \\
\hline MWC (\% of Approved Proposals) & 0 & 49 & 0 & 46 \\
Delay (\% of Approved Proposals) & 0 & &
\end{tabular}

${ }^{a}$ Conditional on approved allocation being a MWC.

${ }^{\mathrm{b}}$ We report only the treatment with low cost of delay $(\delta=0.95)$.

\section{Data Collection, Sample Selection Procedure, and} Methodology

Our data was collected from authors' websites when publicly available. If not, we contacted the corresponding authors directly with all providing their data. An exhaustive search was conducted on the main academic digital repositories searching for the keywords "mul-

\footnotetext{
${ }^{7}$ For the theoretical framework, see Winter (1996).
} 
tilateral bargaining experiments" and "Baron and Ferejohn (1989)" among others. Two research assistants were employed to aid in the search task and data compatibilization process.

In our comprehensive analysis we will delimit our sample of study to treatments in which the SSPE prediction is that all players have the same stationary value of the game. We refer to these treatments as symmetric. Note that this does not preclude asymmetric recognition probabilities when bargaining has an infinite horizon because symmetric stationary values may emerge. However, when there are a finite number of rounds to reach an agreement, we require equiprobable recognition. In these cases, asymmetric recognition yields unequal continuation values.

Our restriction implies that we are choosing treatments with the following parameter configurations:

1. Equal real bargaining power: All members must have the same equilibrium probability of inclusion in a winning coalition. This further excludes treatments where some players have a disproportionate voting weight such as the Apex treatment in Fréchette et al. (2005a) and the veto treatments in Drouvelis et al. (2010) and Kagel et al. (2010).

2. Symmetric disagreement values: If bargaining reaches the final round, or if breakdown occurs as in Miller et al. (2018), we require that all players receive the same payoff.

In keeping as close as possible to the original form of the Baron and Ferejohn game, our included sample of treatments all share the following features:

1. There are at least two rounds of bargaining allowed in a given game.

2. The fund to distribute is exogenous.

3. Subjects have stable group identifiers within a bargaining group

4. Subjects are not identifiable across games in the experiment 
5. Subjects have not participated in previous BF experiments

6. All proposals and voting decisions are made by subjects and not by computers.

Studies marked with ${ }^{* *}$ and $*$ in Table 1 are included in our analysis. Treatments not meeting the conditions above in those studies are excluded.

\section{Analysis of Symmetric Treatments}

Before starting our analysis, a few definitions are necessary. We will refer to a player as being included in the allocation whenever she receives 5 percent or more of the total fund. An MWC is defined as an allocation where exactly the required majority of voters are included in the allocation. An all-way split is one in which all members receive shares greater than or equal to 5 percent of the total fund. Our analysis is robust to considering a strict definition (i.e. share greater than 0 counting as included), but most of the studies consider pittance shares as equivalent to exclusion from the coalition.

Our main analysis will be presented in a series of regression results concerning the main outcome variables (proposer's share, MWCs, and delay) in which we allow for multilevel random effects at the session and subject levels. The regressors for the fixed effect estimation are the BF game parameters (discount factor and group size). When possible, we present results for two subsamples: all proposals and all proposals that were up for a vote.

In our regressions we control for whether or not communication is possible between subjects, learning (a dummy variable for the first three games), round in which the proposal is made, and the show up fee relative to the pie size. ${ }^{8}$ When focusing on proposals selected for voting, we also account for whether the proposal was accepted or not.

\footnotetext{
${ }^{8}$ To calculate the pie size we convert the experimental currency units into local currency. This amount is multiplied times the probability of payment for a given game within the experimental session.
} 


\subsection{Proposer Power}

According to the SSPE, the proposer's share is given by

$$
\text { propshare }=1-\frac{\delta}{\text { group size }}\left(\frac{\text { group size }-1}{2}\right)
$$

where $\frac{\delta}{\text { group size }}$ represents the discounted continuation value of the game (and the minimum amount any rational voter would accept) and $\left(\frac{\text { groupsize-1 }}{2}\right)$ is the total number of votes needed for approval (excluding the proposer). Rearranging equation (1) and taking natural logarithms of both side, we obtain

$$
\ln (1-\text { propshare })=\ln (\delta)+\ln \left(\frac{\text { group size }-1}{2 \times \text { group size }}\right) .
$$

To test whether the theory is useful in explaining the data we estimate the following econometric model:

$$
\ln \left(1-\text { propshare }_{\text {sit }}\right)=\beta_{0}+\beta_{1} \ln \left(\delta_{s}\right)+\beta_{2} \ln \left(\frac{\text { group size }_{s}-1}{2 \times \text { group size }_{s}}\right)+\eta_{i}+\nu_{s}+\epsilon_{\text {sit }}
$$

where $\eta_{i}$ and $\nu_{s}$ are the subject and session-specific random effects and $\epsilon_{s i t}$ is the error

term. Values of $\hat{\beta}_{1}$ and $\hat{\beta}_{2}$ equal to 1 would mean that the data approximates the theoretical predictions.

The results of our estimation are presented in Table 3. We can definitively reject that the SSPE is a good predictor of the observed proposer behavior in the data. The coefficients $\hat{\beta}_{1}$ and $\hat{\beta}_{2}$ are significantly different from 1 (Wald test $p$-value $>0.6$ ).

We now turn to a reduced form estimation of the proposer's share in order to understand how experimental parameters correlate with it. Estimation results presented in Table 4 show that as group size increases from 3 to 5 players, proposers' shares fall (group size of 3 is the base level) by 7.5 percentage points, and by 25 percentage points when group size increases from 5 to 7 . 
Table 3: Structural Estimation of Proposer Behavior

\begin{tabular}{lcccc}
\hline & \multicolumn{2}{c}{$(1)$} & \multicolumn{2}{c}{$(2)$} \\
& \multicolumn{2}{c}{ All Proposals } & \multicolumn{2}{c}{ Voted Proposals } \\
\hline Constant & $-0.981^{* * *}$ & $(0.050)$ & $-1.007^{* * *}$ & $(0.041)$ \\
$\ln (\delta)$ & -0.050 & $(0.076)$ & $-0.149^{* *}$ & $(0.060)$ \\
$\ln \left(\frac{\text { group size }-1}{2 \times \text { group size }}\right)$ & $0.178^{* * *}$ & $(0.028)$ & $0.154^{* * *}$ & $(0.024)$ \\
Communication & $-0.234^{* * *}$ & $(0.043)$ & $-0.250^{* * *}$ & $(0.042)$ \\
First 3 Games & $0.070^{* * *}$ & $(0.013)$ & $0.071^{* * *}$ & $(0.007)$ \\
Round & $0.019^{* *}$ & $(0.008)$ & $0.018^{* * *}$ & $(0.004)$ \\
Communication $\times$ First 3 & $0.145^{* * *}$ & $(0.030)$ & $0.140^{* * *}$ & $(0.027)$ \\
Accepted & & & $0.084^{* * *}$ & $(0.008)$ \\
Show Up Fee / Pie & -0.007 & $(0.009)$ & -0.007 & $(0.005)$ \\
\hline var(Session) & $0.073^{* * *}$ & $(0.013)$ & $0.075^{* * *}$ & $(0.012)$ \\
var(Subject) & $0.137^{* * *}$ & $(0.007)$ & $0.128^{* * *}$ & $(0.005)$ \\
\hline$N$ & 2307 & & 4906 & \\
$\chi^{2}$ & 169.11 & & 376.51 & \\
$\chi^{2}($ LR test Linear vs. RE) & 400.57 & & 1306.68 & \\
\hline
\end{tabular}

Standard errors in parentheses

${ }^{*} p<0.1,{ }^{* *} p<0.05,{ }^{* * *} p<0.01$

The comparative statics from the SSPE predict that the proposer's share falls as players become more patient (negative coefficient). This prediction is corroborated for the sample of selected proposals but not when pooling all proposals. To further investigate the effect of $\delta$, we conduct the same specification with an interaction term between group size and discount factor. We obtain a negative and significant coefficient on the discount factor and group size for both samples (see online appendix).

There is significant evidence that learning takes place in the first three games of the experiments (robust to first 2, 4 and 5 games) as proposers tend to keep shares that are about 4 percentage points smaller on average. We also find that, as bargaining progresses within a given game, proposers take less (between 1 and 2 percent per additional round). One reason for this adjustment taking place can be that, after a rejection, proposers learn that group members are driving a tougher bargain and thus adjust accordingly to enhance chances of being approved. 
Table 4: Multilevel Random Effects Regression for Proposer's Share

\begin{tabular}{lcccc}
\hline & \multicolumn{2}{c}{$(1)$} & \multicolumn{2}{c}{$(2)$} \\
& \multicolumn{2}{c}{ All Proposals } & \multicolumn{2}{c}{ Voted Proposals } \\
\hline Constant & $0.452^{* * *}$ & $(0.034)$ & $0.659^{* * *}$ & $(0.035)$ \\
$\delta$ & $0.065^{*}$ & $(0.037)$ & $-0.075^{* *}$ & $(0.034)$ \\
Group size=5 & $-0.061^{* * *}$ & $(0.015)$ & $-0.079^{* * *}$ & $(0.012)$ \\
Group size=7 & $-0.308^{* * *}$ & $(0.032)$ & $-0.382^{* * *}$ & $(0.027)$ \\
Communication & $0.102^{* * *}$ & $(0.019)$ & $0.108^{* * *}$ & $(0.013)$ \\
First 3 Games & $-0.038^{* * *}$ & $(0.003)$ & $-0.037^{* * *}$ & $(0.006)$ \\
Round & $-0.008^{* * *}$ & $(0.002)$ & $-0.007^{*}$ & $(0.003)$ \\
Communication $\times$ First 3 & $-0.067^{* * *}$ & $(0.013)$ & $-0.064^{* * *}$ & $(0.013)$ \\
Accepted & & & $-0.086^{* * *}$ & $(0.005)$ \\
Show Up Fee / Pie & $0.005^{* *}$ & $(0.002)$ & 0.002 & $(0.004)$ \\
\hline Random Effects & & & & \\
var(Session) & $0.030^{* * *}$ & $(0.005)$ & $0.018^{* * *}$ & $(0.005)$ \\
var(Subject) & $0.066^{* * *}$ & $(0.003)$ & $0.061^{* * *}$ & $(0.003)$ \\
\hline$N$ & 4939 & & 2322 & \\
$\chi^{2}$ & 378.67 & & 671.94 & \\
$\chi^{2}$ (LR test Linear vs. RE) & 1428.47 & & 356.45 & \\
\hline Stanc
\end{tabular}

Standard errors in parentheses.

${ }^{*} p<0.1,{ }^{* *} p<0.05,{ }^{* * *} p<0.01$ 
Conclusion 1. Evidence from a structural estimation shows that the SSPE is not a good predictor for the observed proposer's share. However, the reduced form estimation shows that observed behavior qualitatively approximates the comparative statics of the model: the proposer's share falls with group size and discount factor.

\subsection{Minimum Winning Coalitions}

The proportion of MWCs by group size is displayed in Figure 1 and provides two clear arguments against the SSPE predictions. First, MWCs represent only two thirds of all proposals, far from the 100 percent prediction. Second, group size matters, with MWCs more prevalent in groups of 5 members.

Regression results presented in Table 5 further confirm this finding. The estimated probability of proposing a MWC increases by 10.5 percentage points in groups of 5 members compared to groups of 3 . The effect is non-monotonic in group size, as groups of 7 and 3 are both equally less likely than groups of 5 to form larger coalitions.

There is significant evidence of early learning. In the first three periods of play, the percentage is 13 points lower which is consistent with the observation that the proposer's share also increases with experience.

Conclusion 2. Minimum winning coalitions are the modal allocation (66 percent of all proposals) in accordance with SSPE predictions. Evidence shows that learning occurs after a few games of experience. Contrary to the SSPE predictions the following variables have an effect of the probability of MWC formation: group size (non-monotonic), the discount factor (positive), and communication (positive).

The results presented are robust to considering a strict measure whereby a member is considered as included in the coalition whenever offered a positive share. A regression similar to the one in Table 5 is reported in the online appendix. 
Table 5: Multilevel Random Effects Probit for Minimum Winning Coalitions

\begin{tabular}{lcccc}
\hline & \multicolumn{2}{c}{$(1)$} & \multicolumn{2}{c}{$(2)$} \\
& \multicolumn{2}{c}{ All Proposals } & \multicolumn{2}{c}{ Voted Proposals } \\
\hline Constant & $-0.812^{*}$ & $(0.493)$ & -0.359 & $(0.528)$ \\
$\delta$ & $1.873^{* * *}$ & $(0.539)$ & $1.122^{* *}$ & $(0.511)$ \\
Group size=5 & $0.488^{* *}$ & $(0.216)$ & $0.500^{* * *}$ & $(0.181)$ \\
Group size=7 & -0.289 & $(0.474)$ & -0.423 & $(0.418)$ \\
Communication & $0.973^{* * *}$ & $(0.299)$ & $0.823^{* * *}$ & $(0.225)$ \\
First 3 Games & $-0.851^{* * *}$ & $(0.059)$ & $-0.727^{* * *}$ & $(0.091)$ \\
Round & -0.012 & $(0.038)$ & -0.044 & $(0.061)$ \\
Communication $\times$ First 3 & 0.144 & $(0.245)$ & 0.045 & $(0.249)$ \\
Accepted & & & 0.067 & $(0.095)$ \\
Show Up Fee / Pie & -0.004 & $(0.033)$ & 0.090 & $(0.064)$ \\
\hline Random Effects & & & & \\
var(Session) & $0.144^{* *}$ & $(0.072)$ & 0.015 & $(0.040)$ \\
var(Subject) & $1.498^{* * *}$ & $(0.165)$ & $1.353^{* * *}$ & $(0.195)$ \\
\hline$N$ & 4939 & & 2322 & \\
$\chi^{2}$ & 255.06 & & 112.36 & \\
$\chi^{2}$ (LR test Probit vs. RE) & 1417.37 & & 375.91 & \\
\hline
\end{tabular}

Standard errors in parentheses.

${ }^{*} p<0.1,{ }^{* *} p<0.05,{ }^{* * *} p<0.01$ 


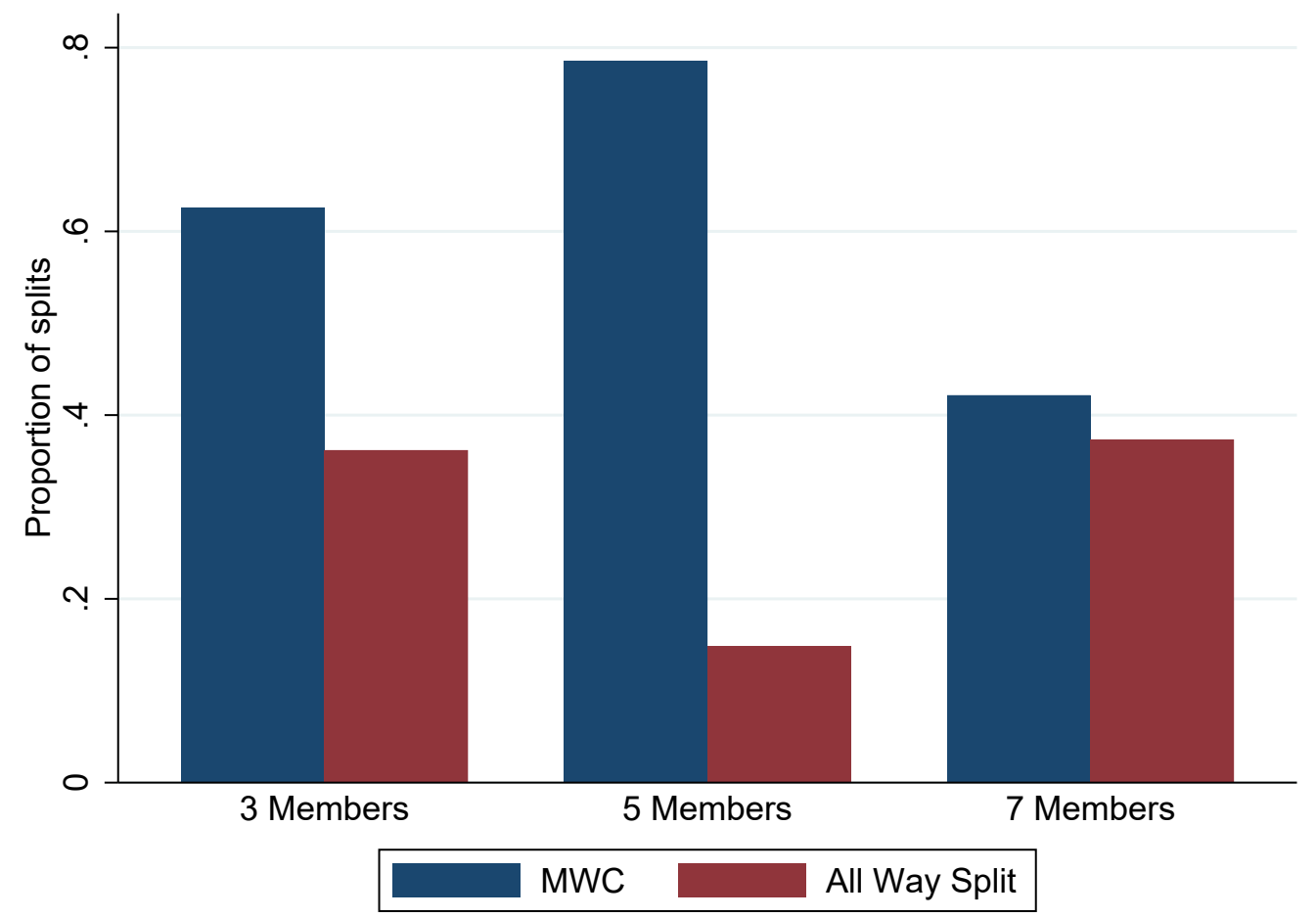

Figure 1: Minimum Winning Coalitions and All-Way Splits

\subsection{Delay}

How likely are groups to delay reaching an agreement beyond the first round of bargaining? To answer this question we conduct a similar regression to those previously presented, with the difference that the unit of observation is a given bargaining group (not an individual). We include session-level random effects but no group random effects as groups are quite unlikely to be the same from one period to the other (most groups only meet once).

The results reported in Table 6 and Figure 2 provide some evidence that an increase in group size, from 3 to 7 members $(p=0.069)$, may negatively affect the probability of a round-one agreement. This result is in line with the findings reported by Miller and Vanberg (2015) of higher rejection rates in groups of 7 compared to groups of 3. However, it should be noted that the evidence is not too strong (noisy estimates for group size 7 due to the small sample size for these groups).

No study so far has reported on the effect of discounting on delay. We find that the 
Table 6: Multilevel Random Effects Probit for Agreement Delay

\begin{tabular}{|c|c|c|}
\hline \multirow[b]{2}{*}{ Constant } & \multicolumn{2}{|c|}{ Accepted Proposals } \\
\hline & $-2.360 * * *$ & $(0.354)$ \\
\hline$\delta$ & $1.756^{* * *}$ & $(0.321)$ \\
\hline Group size $=5$ & 0.179 & $(0.135)$ \\
\hline Group size $=7$ & $0.519^{*}$ & $(0.285)$ \\
\hline Communication & $-0.438^{* * *}$ & $(0.149)$ \\
\hline First 3 Games & 0.036 & $(0.084)$ \\
\hline Communication $\times$ First 3 & $-0.587^{* *}$ & $(0.264)$ \\
\hline Show Up Fee / Pie & -0.020 & $(0.057)$ \\
\hline $\operatorname{var}($ Session$)$ & $0.032^{*}$ & $(0.019)$ \\
\hline$N$ & 2068 & \\
\hline$\chi^{2}$ & 52.54 & \\
\hline$\chi^{2}$ (LR test Probit vs. RE) & 6.68 & \\
\hline
\end{tabular}

Standard errors in parentheses

${ }^{*} p<0.1,{ }^{* *} p<0.05,{ }^{* * *} p<0.01$
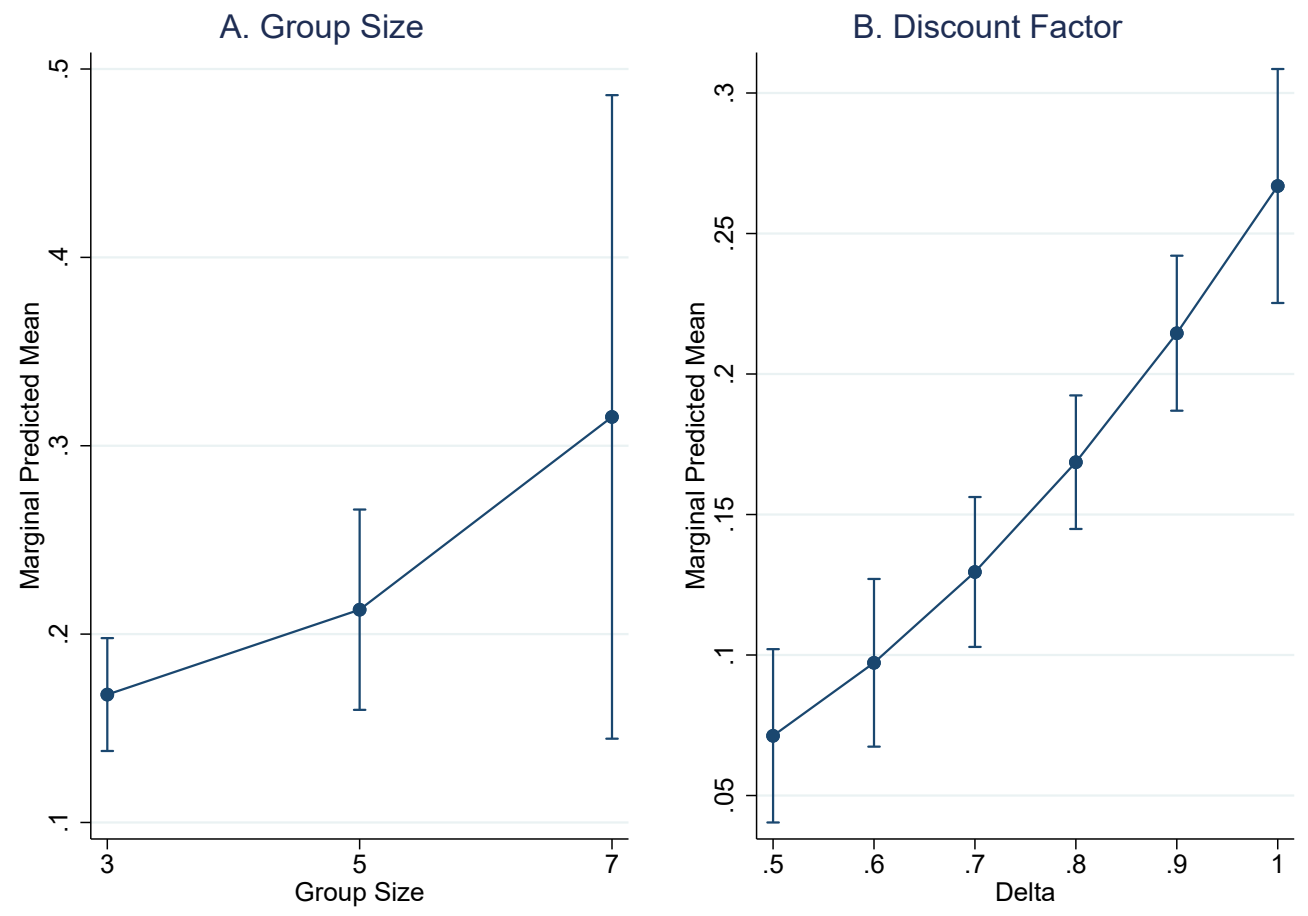

Figure 2: Marginal Probability of Delay 
lower the costs of delay are, the more likely it is that bargaining will extend beyond the first round. While this finding matches one's intuition, it is not predicted by the SSPE.

Agranov and Tergiman (2014) and Baranski and Kagel (2015) have reported that communication reduces the likelihood of delay, although both studies failed to achieve significance at the 5 percent level or better. In our pooled data, we are able to confirm the significance of this effect $(p=0.003)$.

Finally, there is evidence that delay increases with experience. This may be due to two reasons. One is that the proposer's share is growing which leaves less money to convince other voters. The effect can be further exacerbated if subjects also dislike the proposer getting a larger share (aversion to disadvantageous inequality). In our upcoming voting section, where we further explore the determinants of voting, these conjectures are confirmed. ${ }^{9}$

Conclusion 3. The probability of delay in reaching an agreement is (1) lower when subjects may communicate; (2) negatively correlated with the cost of disagreement; (3) positively correlated with group size; and (4) increases with experience. None of these findings are consistent with the SSPE predictions.

\subsection{Voting}

It has been reported throughout the different studies that the main determinant of voting is a player's own share (which we confirm). However, other factors which may play a role in the voting decision have been set forth such as the proposer's share and whether or not the allocation is a MWC, but the results are thus far are ambiguous and not all studies report comparable voting regressions. Furthermore, there is research of which we are aware of that analyzes the effect of group size on voting, and only one study that examines the role of the discount factor (Fréchette and Vespa, 2017).We have excluded this study from our regression analysis because some proposals are made by the computer and subjects responses

\footnotetext{
${ }^{9}$ Another reason is more "statistical" in the sense that as coalitions become less inclusive (which we know happens with experience) a single "no" vote suffices to impede immediate agreement.
} 
Table 7: Multilevel Random-Effects Voting Probit

\begin{tabular}{lcccc}
\hline & \multicolumn{2}{c}{$(1)$} & \multicolumn{2}{c}{$(2)$} \\
& \multicolumn{2}{c}{ All Shares } & \multicolumn{2}{c}{ Included Shares } \\
\hline Constant & -0.208 & $(0.368)$ & 0.246 & $(0.405)$ \\
Own Share & $5.613^{* * *}$ & $(0.243)$ & $4.712^{* * *}$ & $(0.309)$ \\
Prop. Share & -0.080 & $(0.192)$ & $-0.415^{* *}$ & $(0.210)$ \\
$\delta$ & $-1.067^{* * *}$ & $(0.314)$ & $-1.145^{* * *}$ & $(0.348)$ \\
Group size=5 & $-0.360^{* *}$ & $(0.151)$ & 0.084 & $(0.184)$ \\
Group size=7 & $1.604^{* * *}$ & $(0.296)$ & $1.193^{* * *}$ & $(0.346)$ \\
$5 \times$ Own Share & $4.183^{* * *}$ & $(0.367)$ & $1.547^{* * *}$ & $(0.484)$ \\
$7 \times$ Own Share & $-6.572^{* * *}$ & $(1.094)$ & $-5.410^{* * *}$ & $(1.321)$ \\
Voting Weight & $-1.446^{* * *}$ & $(0.446)$ & $-1.510^{* * *}$ & $(0.468)$ \\
Communication & $0.714^{* * *}$ & $(0.154)$ & $0.484^{* *}$ & $(0.192)$ \\
Communication $\times$ Own Share & $-1.854^{* * *}$ & $(0.434)$ & $-0.955^{*}$ & $(0.560)$ \\
Round & $0.073^{* *}$ & $(0.035)$ & $0.085^{* *}$ & $(0.038)$ \\
MWC (1=yes) & -0.009 & $(0.063)$ & $0.453^{* * *}$ & $(0.082)$ \\
First 3 Games & 0.074 & $(0.049)$ & 0.075 & $(0.051)$ \\
Communication $\times$ First 3 & -0.027 & $(0.103)$ & -0.029 & $(0.108)$ \\
Show Up Fee / Pie & $-0.119^{* * *}$ & $(0.036)$ & $-0.115^{* * *}$ & $(0.038)$ \\
\hline Random Effects & & & & \\
var(Session) & $0.035^{* *}$ & $(0.014)$ & $0.047^{* * *}$ & $(0.018)$ \\
var(subject) & $0.139^{* * *}$ & $(0.021)$ & $0.159^{* * *}$ & $(0.024)$ \\
\hline$N$ & 6885 & & 5639 & \\
$\chi^{2}$ & 1691.74 & & 749.14 & \\
$\chi^{2}$ (LR test Probit vs. RE) & 168.15 & & 190.40 & \\
\hline Stanard ero & & & &
\end{tabular}

Standard errors in parentheses

$* p<0.1,{ }^{* *} p<0.05,{ }^{* * *} p<0.01$

are related to their beliefs about the origin of the proposal.

We build on the econometric models of Fréchette et al. (2005a) and Fréchette and Vespa (2017) by estimating a random effects voting probit (two-level model) in which the the probability of voting in favor is a function of own share (as a proportion of the total fund), the proposer's share (as a proportion of the total fund), group size and it's interaction with own share, and the discount factor. Since we also include in our analysis treatments with asymmetric voting weights, we incorporate this variable to account for the fact the nominal bargaining power may affect voting decisions. ${ }^{10}$ We include the usual controls we have in

\footnotetext{
${ }^{10}$ The voting weight is the proportion of votes held by the subject.
} 
our previous estimations as well as a dummy variable taking the value of 1 whenever the allocation is a MWC. We also include an interaction for the communication dummy with own share.

Table 7 shows the estimation results for two samples: the first column includes all proposals that were voted on and the second column includes only those players whose offered shares are greater than 5 percent of the fund (virtually no one votes in favor when offered such low shares).

As expected, own share is positive and significant. Subjects in groups of 5 are less willing to vote in favor than those in groups of 3 and 7 and put more weight on their own share, while subjects in groups of 7 are more agreeable than smaller groups and put less weight on their own share. This is consistent with the findings that MWCs are higher in groups of 5, where more resources are split among a smaller group. It appears that subjects anticipate the strength with which own share matters, so that offering more resources to less players dominates diluting incentives among more-than-minimal coalitions.

Previous evidence regarding the effect of the proposer's share has been inconclusive. For example, Fréchette et al. (2005b) only find a significant effect for their symmetric treatment while Fréchette et al. (2005a) only find a significant effect for their apex treatment, and Fréchette and Vespa (2017) report significance in only some econometric specifications. All these studies have reported a negative effect and our pooled analysis confirms its statistical significance $(p<0.05)$ for the subsample of included voters, but not when including all voters. Thus, conditional on being invited into the coalition, voters appear to be negatively affected by the proposer's share. This relationship helps explain why (almost) equal sharing is the modal split within MWCs.

Fréchette and Vespa (2017) report a negative relationship between the discount factor and voting, which we verify in our pooled analysis. Thus, their finding is not driven by the fact that human and computer proposals are unidentifiable to subjects. This negative relationship is consistent with the fact that delay is more likely to occur as the discount 
factor increases as previously reported.

The overall effect of communication is positive: subjects are unconditionally more willing to vote in favor when they can communicate. Importantly, the interaction with own share is negative. This may be evidence of an underlying psychological effect of communication since it implies that players value the same offered share differently simply because they were able to exchange messages with the proposer. These two effects, coupled with the evidence from chat transcripts described in Agranov and Tergiman (2014) and Baranski and Kagel (2015), are consistent with proposers being able to extract larger shares when they can communicate with voters.

We find evidence that nominal voting weights affect voting decisions, despite theory predicting that only real bargaining power differences should do so. The study by Fréchette et al. (2005b) in which nominal shares are varied, does not estimate the effect of voting weights on voting behavior. Thus, we uncover an illusion of power derived from voting shares, which is in line with the psychological theory of inequity (Adams, 1965) and the principle of proportionality in payoff distribution and coalition formation according to Gamson (1961), as Diermeier and Morton (2005) have previously set forth as a potential explanation of behavior. ${ }^{11}$

Results regarding the effect of whether or not the allocation is a MWC remain unclear. For example, Baranski and Kagel (2015) report a negative and significant effect, while Fréchette and Vespa (2017) finds both negative and positive (non-significant) effects. Excluding this dummy variable from our analysis does not affect the significance of our estimations and previously reported results.

Conclusion 4. The probability of voting in favor is (1) positively correlated with own share; (2) positively correlated with the cost of delay; (3) non-monotonic in group size; (4) positively correlated with the possibility to communicate; and (5) negatively correlated with the proposer's share for voters who are part of the coalition formed by the proposer.

\footnotetext{
${ }^{11}$ See Maaser et al. (2019) for a recent experiment in which voting weights are varied. A similar conclusion is reached as the one derived from our comprehensive analysis.
} 


\subsection{Disagreement paths: History-dependent behavior}

For the most part, the literature has not studied in detail the how previous bargaining rounds affect future bargaining behavior within a committee. Given that the stationary prediction hinges on history independence, it becomes crucial to investigate whether subjects actually behave in such way.

In this section we focus on the relationship between failed first-round proposals and second-round bargaining behavior, in order to capture reciprocal behavior (if any) in the most transparent manner. ${ }^{12}$ Our main variable of interest is the average offer to round-one proposers by previous non-proposers.

Figure 3 provides clear evidence of reciprocity at play, both negative and positive. Subjects who supported a preceding proposal offer a higher share to the proposer in the next round (42 percent) than what they offer to previous non-proposers on average (21 percent). On the other hand, subjects who did not support the previous proposal retaliate against the proposer. They offer on average twice as much to non-proposers than to previous proposers. Regression analysis robustly confirms the statistical significance of these results. ${ }^{13}$

We investigated if subjects who showed support for the failed proposal were also punished by round two proposers (see online appendix). While results from our regressions show a negative relationship between voting in favor for a failed proposal and the share offered by the next proposer, it was not significant $(p=0.62)$.

Conclusion 5. Proposing behavior following a disagreement displays strong history-dependence and, as such, is inconsistent with stationary strategies. Subjects who rejected a previous proposal offer lower amounts to the previous proposer while those who supported the proposal reciprocate positively. We find no evidence of punishment directed towards supporters of failed proposals.

\footnotetext{
${ }^{12}$ Allowing for more rounds of bargaining obscures which piece of history is relevant for reciprocating. ${ }^{13}$ See Table 8 in Appendix A.
} 
Figure 3: Shares offered in Round 2 Following a Rejection in Round 1.
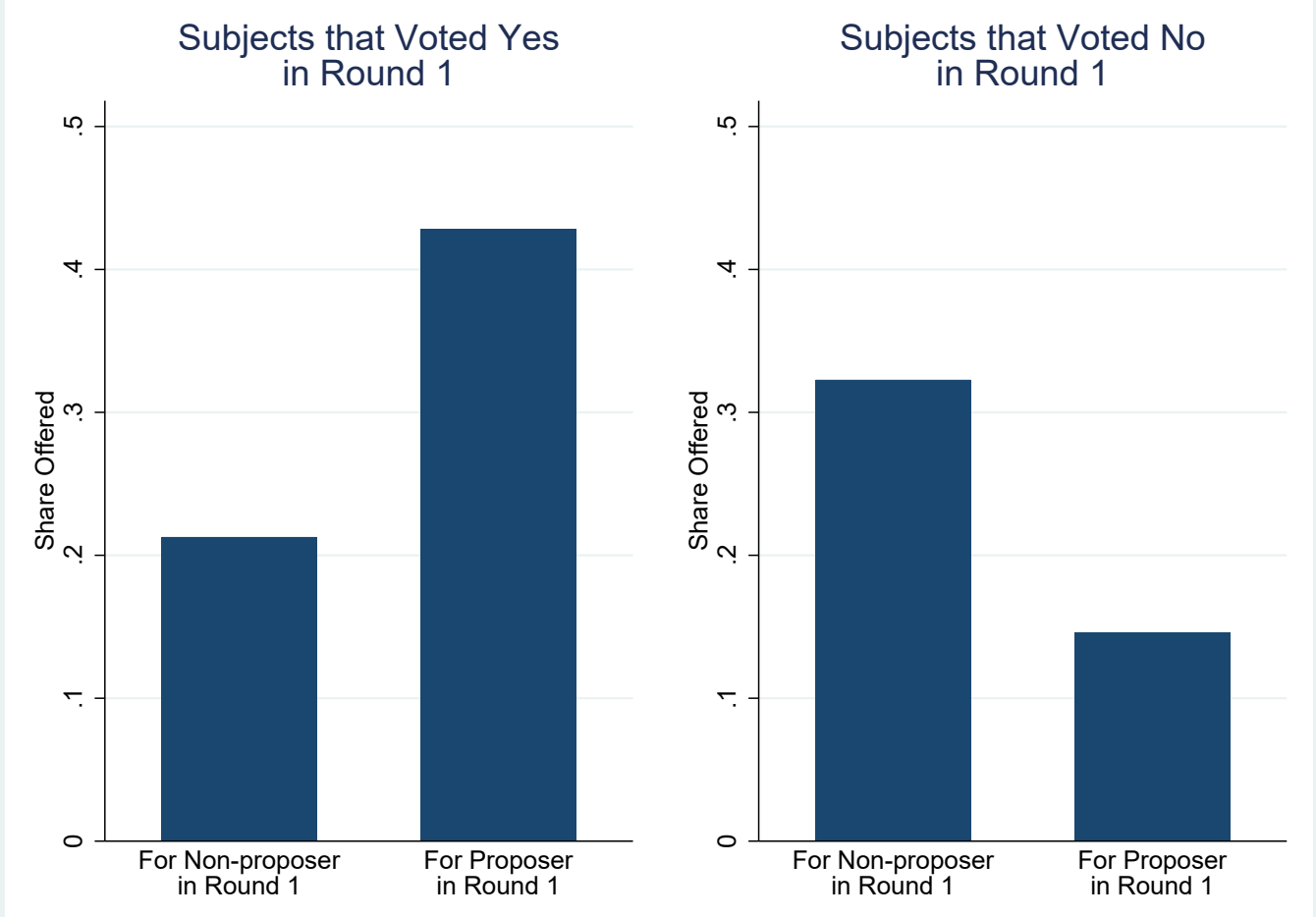

Notes: This figure shows the average share offered in round 2 to members who did not propose in round 1 (first bar of each panel) and for proposers in round 1 (second bar of each panel). Proposals made in round 2 by round 1 proposers are excluded. The left panel shows the data for subjects who supported the failed proposal and the right panel is for those who voted against the previous proposal.

\section{Discussion and Concluding Remarks}

Several attempts have been made to reconcile theory with experimental results in the Baron and Ferejohn (1989) game. For example, Montero (2007) keenly solves the SSPE with other-regarding preferences such as those specified by Fehr and Schmidt (1999) or Bolton and Ockenfels (2000). Under reasonable parameters, the SSPE predicts even a larger share for the proposer, which paradoxically increases inequality compared to the standard case. A similar result obtains when risk aversion is incorporated into players' utility functions (Harrington, 1990). 
Nunnari and Zapal (2016) present an elegant model in which players have biased assessments of their chance of proposing. Conditional on not being the current proposer, players incorrectly believe their odds of proposing next round are higher (i.e. fall prey of the gambler's fallacy). Theoretically, this predicts higher continuation values for non-proposers which leads to reduced proposer power. Additionally, Nunnari and Zapal compute quantal response equilibrium voting strategies and find that, combined with the gambler's fallacy in the proposer recognition process, one may simulate behavior that generates a fraction of proposals having more than minimal coalition partners (in addition to moderate proposer power).

Our empirical findings suggest that a primary source of the divergence between data and SSPE theoretical predictions is the assumption that players are using history-independent strategies. Retaliation and positive reciprocity are largely at play, thus the stationarity refinement is inaccurate and should be disposed of when theorizing about subject behavior if one seeks to realistically capture behavior. Importantly, such reciprocal strategies are also present in the treatments with communication. This means that communication may lead to outcomes that resemble those predicted by the SSPE but not because of the strategies players are using.

The model of Baron and Ferejohn is one of complete information and there is no space for disagreement to arise. Nonetheless, there are two findings that support the conjecture that incomplete information about others' preferences may impact bargaining outcomes. First, when communication is possible, disagreement rates are reduced. The evidence shows that subjects tend to state their willingness to accept and that there are differences between subjects in this regard. Second, when a proposal is rejected, we see that the proposer's share in subsequent rounds is lower. This can be interpreted as if subjects are adjusting their proposals because they updated their beliefs about their group members' willingness to accept.

In our comprehensive analysis we have uncovered several effects previously unreported 
in the literature regarding the impact of group size and discount factor on outcomes and voting strategies. It is our hope that future theoretical and experimental work can help us make sense of the stylized results reported here. 


\section{REFERENCES}

Adams, J. S. (1965). Inequity in social exchange. In Advances in experimental social psychology, volume 2, pages 267-299. Elsevier.

Agranov, M. and Tergiman, C. (2014). Communication in multilateral bargaining. Journal of Public Economics, 118:75-85.

Baranski, A. (2016). Voluntary contributions and collective redistribution. American Economic Journal: Microeconomics, 8(4):149-73.

Baranski, A. (2019). Endogenous claims and collective production: an experimental study on the timing of profit-sharing negotiations and production. Experimental Economics. https://doi.org/10.1007/s10683-018-9591-2.

Baranski, A. and Cox, C. (2019). Communication in multilateral bargainin with joint production. NYUAD Social Science Working Paper 32 https://nyuad.nyu.edu/content/dam/ nyuad/academics/divisions/social-science/working-papers/2019/0032.pdf. Last accessed December 1, 2019.

Baranski, A. and Kagel, J. H. (2015). Communication in legislative bargaining. Journal of the Economic science Association, 1(1):59-71.

Baron, D. P. and Ferejohn, J. A. (1989). Bargaining in legislatures. American political science review, 83(4):1181-1206.

Bradfield, A. J. and Kagel, J. H. (2015). Legislative bargaining with teams. Games and Economic Behavior, 93:117-127.

Diermeier, D., Gailmard, S., et al. (2006). Self-interest, inequality, and entitlement in majoritarian decision-making. Quarterly Journal of Political Science, 1(4):327-350. 
Diermeier, D. and Morton, R. (2005). Experiments in majoritarian bargaining. In Social choice and strategic decisions, pages 201-226. Springer.

Drouvelis, M., Montero, M., and Sefton, M. (2010). Gaining power through enlargement: Strategic foundations and experimental evidence. Games and Economic Behavior, 69(2):274-292.

Eraslan, H. and Evdokimov, K. S. (2019). Legislative and multilateral bargaining. Annual Review of Economics, 11(1):443-472.

Fréchette, G., Kagel, J. H., and Morelli, M. (2005a). Behavioral identification in coalitional bargaining: An experimental analysis of demand bargaining and alternating offers. Econometrica, 73(6):1893-1937.

Fréchette, G., Kagel, J. H., and Morelli, M. (2005b). Nominal bargaining power, selection protocol, and discounting in legislative bargaining. Journal of Public Economics, 89(8):1497-1517.

Fréchette, G. R., Kagel, J. H., and Lehrer, S. F. (2003). Bargaining in legislatures: An experimental investigation of open versus closed amendment rules. American Political science review, 97(2):221-232.

Fréchette, G. R. and Vespa, E. (2017). The determinants of voting in multilateral bargaining games. Journal of the Economic Science Association, 3(1):26-43.

Gamson, W. A. (1961). A theory of coalition formation. American Sociological EReview, pages $373-382$.

Harrington, J. E. (1990). The role of risk preferences in bargaining when acceptance of a proposal requires less than unanimous approval. Journal of Risk and Uncertainty, 3(2):135154. 
Kagel, J. H., Sung, H., and Winter, E. (2010). Veto power in committees: an experimental study. Experimental Economics, 13(2):167-188.

Maaser, N., Paetzel, F., and Traub, S. (2019). Power illusion in coalitional bargaining: An experimental analysis. Games and Economic Behavior, 117:433-450.

McKelvey, R. D. (1991). An experimental test of a stochastic game model of committee bargaining. In Palfrey, T. R., editor, Contemporary Laboratory Research in Political Economy. Ann Arbor: University of Michigan Press.

Miller, L., Montero, M., and Vanberg, C. (2018). Legislative bargaining with heterogeneous disagreement values: Theory and experiments. Games and Economic Behavior, 107:60-92.

Miller, L. and Vanberg, C. (2013). Decision costs in legislative bargaining: an experimental analysis. Public Choice, 155(3-4):373-394.

Miller, L. and Vanberg, C. (2015). Group size and decision rules in legislative bargaining. European Journal of Political Economy, 37:288-302.

Montero, M. (2007). Inequity aversion may increase inequity. The Economic Journal, 117(519):C192-C204.

Nunnari, S. and Zapal, J. (2016). Gambler's fallacy and imperfect best response in legislative bargaining. Games and Economic Behavior, 99:275-294.

Palfrey, T. R. (2016). Experiments in political economy. In The Handbook of Experimental Economics, volume 2, pages 347-434. Princeton University Press.

Winter, E. (1996). Voting and vetoing. American Political Science Review, 90(4):813-823.

\section{A Additional Tables}


Table 8: Shares offered in round 2 by subjects that did not propose in round 1

\begin{tabular}{lcc}
\hline & Dep. Var.: Offered Share \\
\hline Constant & $0.403^{* * *}$ & $(0.004)$ \\
Share of previous proposer $(=1$ if yes $)$ & $-0.212^{* * *}$ & $(0.013)$ \\
Proposer Voted Yes in Round $1(=1$ if yes $)$ & $-0.023^{* * *}$ & $(0.007)$ \\
Of previous prop. $\times$ Voted Yes & $0.106^{* * *}$ & $(0.030)$ \\
$\delta$ & 0.001 & $(0.001)$ \\
Group size=5 & $-0.161^{* * *}$ & $(0.002)$ \\
Communication & 0.000 & $(0.000)$ \\
Show Up Fee / Pie & 0.000 & $(0.000)$ \\
\hline$N$ & 1929 & \\
$\mathrm{R}^{2}$ & 0.29 & \\
\hline
\end{tabular}

Standard errors clustered at the subject level in parentheses.

${ }^{*} p<0.1,{ }^{* *} p<0.05,{ }^{* * *} p<0.01$

Table 9: Multilevel Random Effects Regression for Proposer's Share with Interactions

(1)

$(2)$

Accepted Proposals All Proposals

\begin{tabular}{lcccc}
\hline Constant & $0.859^{* * *}$ & $(0.116)$ & $0.819^{* * *}$ & $(0.100)$ \\
$\delta$ & $-0.333^{* *}$ & $(0.153)$ & $-0.237^{*}$ & $(0.129)$ \\
Group size & $-0.119^{* * *}$ & $(0.0253)$ & $-0.115^{* * *}$ & $(0.0245)$ \\
$\delta \times$ Group size & $0.103^{* * *}$ & $(0.0362)$ & $0.0968^{* * *}$ & $(0.0339)$ \\
First 3 Games & $-0.0571^{* * *}$ & $(0.00756)$ & $-0.0432^{* * *}$ & $(0.00368)$ \\
Communication & $0.120^{* * *}$ & $(0.0234)$ & $0.118^{* * *}$ & $(0.0224)$ \\
Communication $\times$ First 3 & $-0.0503^{* * *}$ & $(0.0136)$ & $-0.0607^{* * *}$ & $(0.0113)$ \\
Round & -0.00226 & $(0.00231)$ & $-0.00321^{* *}$ & $(0.00163)$ \\
Accepted & & & $-0.0417^{* * *}$ & $(0.00521)$ \\
Show Up Fee / Pie & -0.00317 & $(0.00511)$ & 0.00323 & $(0.00218)$ \\
\hline Ran. Effects Estimation & & & & \\
var(Session) & $-3.379^{* * *}$ & $(0.239)$ & $-3.227^{* * *}$ & $(0.160)$ \\
var(Subject) & $-2.634^{* * *}$ & $(0.0515)$ & $-2.666^{* * *}$ & $(0.0400)$ \\
\hline$N$ & 1598 & & 4523 & \\
$\chi^{2}$ & 225.6 & & 407.0 & \\
$\chi^{2}$ (LR test Linear vs. RE) & 490.4 & & 1556.2 & \\
\hline Stan & & & &
\end{tabular}

Standard errors in parentheses

${ }^{*} p<0.1,{ }^{* *} p<0.05,{ }^{* * *} p<0.01$ 